\title{
Research on Strategic Management of the Enterprise during the COVID-19__ ViacomCBS as an Example
}

\author{
Tongchuan $\mathrm{Hu}^{1,{ }^{,}, \dagger}$, Zhigu Ran ${ }^{2, *, \dagger}$, Jialu Zhao ${ }^{3, *, \dagger}$ \\ ${ }^{1}$ International Department of Shude High School, 670041, Chengdu, China \\ ${ }^{2}$ Beijing Haidian Foreign Language Academy, 100097, Beijing, China \\ ${ }^{3}$ Ranney School, 07724, New Jersey, United States of America \\ *Corresponding author. Email: guanghua.ren@gecacdemy.cn \\ These authors contributed equally.
}

\begin{abstract}
Under the impact of COVID-19, the media industry has been hit to a large extent, but also found a new business opportunity -- streaming video services -- and created a new business model. Taking ViacomCBS, a media company, as an example, this paper analyzes and discusses the strengths, weaknesses, opportunities, and threats that ViacomCBS faces in the context of COVID-19 through SWOT analysis. Despite having flaws in recent streaming strategy and relatively limited funding resources and room for growth, ViacomCBS's extensive consumer base, an enormous pool of resources, powerful distribution network, healthy financial position, and potentials for the integrated business model all add up to promise tremendous growth and success in the future. Based on the results, this paper provides a new research background for the theory of corporate strategic management and expands the application of its theory in the media industry, and also provides practical support for investors.
\end{abstract}

Keywords: Covid-19, ViacomCBS, strategic management, SWOT analysis.

\section{INTRODUCTION}

During the Covid-19 crisis, the industry has suffered from insufficient viewers in the cinema. In replacement, some companies have taken actions to the development of more practical and fitting features or apps, some of which have stuck out, like Netflix, Hulu, Viacom CBS, etc. In this paper, the media company selected as the research object is Viacom CBS, which has found its major success in December 2019. In the era of coronavirus, Viacom CBS has taken the form of an online streaming site. Also, it has taken advantage of a large number of registered trademarks and ownerships of various TV series. The biggest advantage in their possession is the multiple companies they own. The abrupt appearance of the Covid-19 seriously strikes the economy universally. Bringing work home, some of the laborers even lost their jobs and spent the hardest times in their lives. When many other companies have encountered such a large decline in their user numbers, Viacom CBS has only suffered from a little decline in users for their well-balanced business structure.

The impact that the Covid-19 has brought to the market is the decline of the business value of all industries. The media industry has seen a major decline in their audiences offline, which triggers some companies to develop a line of streaming services. They wanted people to keep paying them even if they do not have a chance to take a walk into the theatre. The streaming service has met their boom in increasing people start to follow up with the TV series and be accustomed to utilizing various platforms.

The consequence of COVID-19 for corporations is their temporal loss of money. Some new companies in the media industry may be affected by the decline of audiences, which could directly lead to business failure. However, for large companies, this is an opportunity to discover new fields of media and make it one of their sources of total revenue.

This paper adopts the theory of strategic management and reviews the current research situation from stages, schools, and research in recent years.

Alfred D. Chandler, a well-known American management historian, defines "strategy" as "the determination of the basic long-term goals and objectives of an enterprise, and the adoption of courses of action and the allocation of resources for carrying out 
these goals" [1]. Henry Mintzberg describes "Enterprise Strategy" as a 5Ps of strategy, namely "Plan", "Pattern", "Position", "Perspective", and "Ploy" [2].

"Enterprise Strategy" theory is divided into four major development stages.

The 1930s was the first stage. Scholars, notably Michael Porter, sum up the early ideas to three perspectives: (1) six categories of industrial enterprises activities (technical activities, financial activities, Security activities, accounting activities, and management activities) and five management functions (planning, organization, command, coordination, and control) proposed by French management expert Henri Fayol, (2) American management scientist Chester Irving Barnard separates organization theory from management theory and strategy theory for the first time, and (3) American scholar Kenneth R. Andrews divides strategy into four aspects (market opportunities, company strength, personal values and aspirations, and social responsibility). He advocates that companies obtain competitive advantages through the allocation of resources to form unique capabilities [3].

The second stage is the traditional strategy theory stage in the 1960s. Strategic management gradually forms ten schools-such as Kenneth R. Andrews's SWOT analysis model, Igor Ansoff's planning school, and Michael E. Porter's positioning school famous for its Five Forces Model-and each put forward their propositions based on different strategic perspectives [4].

The third stage is the theoretical stage of competitive strategy in the 1980s. In this stage, the focus of research shifts to practical enterprise competition, and two schools emerge, namely, the industry structure school founded by Michael Porter and the resource school proposed by CK Prahalad and Gary Hamel in The Core Competence of the Corporation [5].

The fourth stage is the theoretical stage of dynamic competition strategy in the 21 st century; this proposition is mainly embodied in grasping and adjusting the competitive advantages of enterprises from the perspective of the chain interaction of competitive behaviors among competitors. Enterprise strategic management is mainly divided into three theoretical viewpoints: industrial basis, resource basis, and system basis [6].

Based on previous research, in recent years, domestic and foreign scholars have conducted further in-depth research on internal control theory. Based on control theory and enterprise strategic management theory, Zha Jianqiu, Zhang Qiusheng, and Zhuang Jian conclude that the performance of strategic internal control system and enterprise value has a significant positive correlation: the quality of enterprise strategic internal control will affect enterprise strategic execution performance and, eventually, enterprise value [7]. Wang Qing carries out a case study of financial strategic management from the perspective of internal control, concluding that good internal control can enhance the financial strategic management capabilities of commercial banks and effectively promote the implementation of commercial banks' financial strategies to help commercial banks achieve sustainable asset appreciation [8].

According to the literature review, the majority of existing strategic management theories are studies carried out under normal economic conditions, but there are few applications and research on the strategic theories during the COVID-19 crisis. In addition, among the existing research objects of strategic management theory, few researches are focusing on the media industry. Based on this, this paper takes the COVID-19 crisis as the research background, the media industry as the research object, and ViacomCBS companies as the representative, utilizing qualitative research methods to conduct in-depth research on the strategic issues of the media industry.

\section{DATA AND METHOD}

\subsection{Data}

\subsubsection{Streaming Media Base}

ViacomCBS is in a possession of a multiple Streaming Media Base. Like Netflix and Hulu, the other streaming platforms, ViacomCBS provides the people with a variety of TV shows and series of streaming videos with membership required. People would have to make subscriptions to the company and they would get a month or a season to a year's use of this very product they were subscribed to. Another advantage for ViacomCBS is the company is already in one piece unlike the other companies such as Netflix and Hulu which were brought by other media giants afterward. ViacomCBS is more flexible and easily manageable.

\subsubsection{Streaming Media Base}

"ViacomCBS could also increasingly diversify its mix of content partners by striking licensing or output deals with a range of regional or local SVOD worldwide. The strategy also allows ViacomCBS to benefit from proliferating opportunities tied to the global growth of streaming video viewing" [9]. This made contributions to the prevention of other companies trying to take advantage of the company itself.

\subsubsection{The Opening of a Free Platform}

The free streaming platform "Pluto" was launched by ViacomCBS as well. Users could watch free videos 
and shows with advertisements attached to them. When people notice that the videos are for free, they are easily bought into it and would give the advertisers chances to promote their products to the users. People would unintentionally buy into the advertisements while watching what they were watching.

\subsubsection{The Diverse Media Branches}

ViacomCBS is a giant in the industry because it covers a big range of media branches such as the CBS News, Comedy Central, Nickelodeon, and Paramount studios. More importantly, the company would not only publish TV series and movies for the company itself only. They put the projects into makings and sell them to other companies for profits. "Together, the ViacomCBS library now includes more than 140,000 TV episodes and 3,600 movies, which it can theoretically parse out to regional streamers in local markets around the world" [10].

\subsection{Method}

The SWOT could be simply broken down into the definition of Strengths, Weaknesses, Opportunities, and Threats [11]. Researchers would follow these points to make the creation of a balanced thesis. They would make comparisons between companies to see their advantages and disadvantages; to see potential risks and competitors that could make possible entries to the industries. With the SWOT being analyzed, the company could see its future to be brighter and make its approaches more easily. Therefore, making the SWOT analysis is more necessary in the industry.

Some methods and strategies that ViacomCBS took to take their advancements, and leading places in the media industries are its strong media streaming service and abilities and multi-form of media shown by the different branches of media: Comedy, News as well as Child Shows. There are several cases and examples that could be provided to show that the method of ViacomCBS is one of a kind in the industry and to its very level of effectiveness.

\section{RESULTS AND DISCUSSION}

This part utilized SWOT analysis to analyze the strengths, weaknesses, opportunities, and threats for ViacomCBS for the study of its business strategy.

\subsection{Strengths}

\subsubsection{Large Customer Base}

ViacomCBS owns the most-watched television network in the US and is one of the world's largest libraries of entertainment content. Some division brands of ViacomCBS are effective and performing well in achieving their market position. For instance, Pluto TV licenses its content directly from providers, and as of March 2020 has dealt with 170 content partners providing more than 250 channels and 100,000 unique hours' worth of programming. Its content is available via its website and supported apps. Paramount+, Showtime, and PlutoTV have 36 million global subscribers and nearly 50 million. Global monthly active users.

\subsubsection{Large Resources Pool and Strong Distribution Networks}

ViacomCBS owns one of the world's largest entertainment contents libraries through its various brands. Like, ViacomCBS's PlutoTV offers over 250 live TV channels and has more than 400 global content partners. ViacomCBS's strong distribution network can help it reach more customers in foreign countries. For instance, MTV is the world's most widely distributed music video cable network, reaching 384 million homes in 140 countries. Nickelodeon Children's Network is watched by 300 million households. Also, BET, the largest African American cable TV channel in the US, reaches 30 countries in Europe and 36 in Africa. ViacomCBS also achieves synergy after acquisition. It can share resources such as content or employees to achieve greater success. "This is a historic moment as two iconic companies come together to form one of the most important content producers and providers in the world," Bob Bakish, president and CEO of ViacomCBS said, "By combining the complementary assets, capabilities and talent teams of CBS and Viacom, ViacomCBS will create and deliver premium content for its platform."

\subsubsection{Healthy Financing Position}

ViacomCBS has an increase in the current ratio from 1.32 at the end of FY2019 to 1.78 at the beginning of FY2021. From FY2019 to FY2020, a surge of its shortterm investments from $\$ 632$ million to $\$ 2,984$ million, resulting in a growth of $15.8 \%$ in current assets (from $\$ 11.90 B$ in FY2019 to $\$ 15.49 B$ in FY2021). See Table 1 [12]. The jump of current assets finally contributes to a higher current ratio(current ratio=current assets/current liabilities). The increase in the current ratio suggests a stronger liquidity position of ViacomCBS, which means it has a more significant margin of safety concerning its ability to pay off current liabilities. Also, a high liquidity ratio will help ViacomCBS to attract more investors due to its healthy financial position.

Table 1 ViacomCBS current ratio historical data.

\begin{tabular}{cccc}
\hline Date & $\begin{array}{c}\text { Current } \\
\text { Assets }\end{array}$ & $\begin{array}{c}\text { Current } \\
\text { Liabilities }\end{array}$ & $\begin{array}{c}\text { Current } \\
\text { Ratio }\end{array}$ \\
\hline $12 / 31 / 2019$ & $\$ 11.90 \mathrm{~B}$ & $\$ 9.05 \mathrm{~B}$ & 1.32 \\
\hline
\end{tabular}




\begin{tabular}{llll}
\hline $03 / 31 / 2020$ & $\$ 10.41 \mathrm{~B}$ & $\$ 8.53 \mathrm{~B}$ & 1.22 \\
$06 / 30 / 2020$ & $\$ 12.44 \mathrm{~B}$ & $\$ 7.99 \mathrm{~B}$ & 1.56 \\
$09 / 30 / 2020$ & $\$ 13.16 \mathrm{~B}$ & $\$ 7.76 \mathrm{~B}$ & 1.70 \\
$12 / 31 / 2020$ & $\$ 13.78 \mathrm{~B}$ & $\$ 8.30 \mathrm{~B}$ & 1.66 \\
$03 / 31 / 2021$ & $\$ 15.49 \mathrm{~B}$ & $\$ 8.70 \mathrm{~B}$ & 1.78
\end{tabular}

\subsubsection{Potentials of integrated business model}

ViacomCBS 's unique hybrid model is likely to help the company win favor in both developed and emerging markets in the future. The combined business model is called "SOVD+AVOD". SVOD refers to subscription video on demand, which means paid subscription plans. AVOD refers to advertising-based video on demand, which means the free services with advertisements. ViacomCBS chooses multi-channel to reach more people. The company is well-positioned to meet the needs of two kinds of users who are willing to pay a subscription fee to bypass commercial breaks, as well as those who accept ads, as long as the platform is free. Thus, by providing customers with more options, ViacomCBS can maintain customer loyalty and avoid losing customers to other television services.

\subsection{Weaknesses}

\subsubsection{Weak Financial Capacity as a Latecomer in Streaming}

ViacomCBS's stock soared early in 2021 in the hope that streaming would reshape the industry. However, shares may have gotten ahead of themselves, and Paramount+ (owned by ViacomCBS) still has a long way to go before being considered a streaming powerhouse. The investors are more willing to bet on the market leaders, such as Disney and Netflix since they are too large to be taken down. Thus, to avoid the risk, fewer investors will be likely to purchase ViacomCBS's stock than its competitors.

\subsubsection{Share Price Is Overvalued}

Because the stock price had grown significantly, the management planned to raise close to $\$ 3$ billion by issuing more shares. As of March 22nd, the stock was selling at $\$ 85$ per share, a $15 \%$ reduction to the issue price of $\$ 100$. Commentary from influential Wall Street research firms stated that the company's management did not believe the recent rise in the stock price to $\$ 100$ was justified. This information combined with the fact that the new issue would attribute to the dilution of shareholders' value, causing a sharp reversal in fortune, which is reflected as a loss of half of the value for ViacomCBS's stock in the last three months, falling from $\$ 100.34$ to around $\$ 40.10$. The slump in the prices of ViacomCBS's stock will trigger threats to its sales of $\$ 3$ billion stock. "We think the liquidation trade could pose a lingering near-term overhang on the shares, potentially compromising (if not jeopardizing) the pending equity offerings," Tuna Amobi, CFRA Research analyst, wrote. See Figure 1 [13].

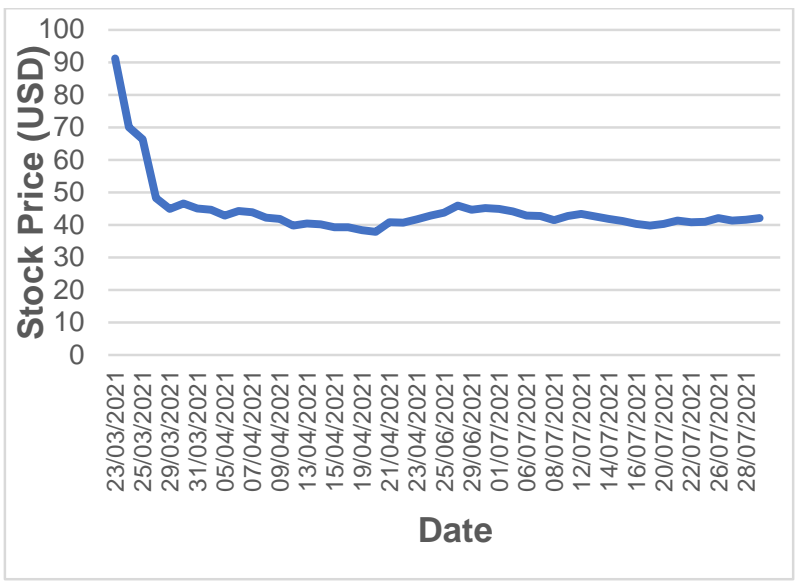

Figure 1 CBS corporation common stock from Mar 2021 to Jul 2021.

\subsubsection{Failure of New Streaming Strategy}

Bob Bakish, CEO of ViacomCBS, said "Our (streaming) strategy is to maximize the value of content by reaching the largest audience." ViacomCBS will retain its strong IP, like Star Trek, while licensing out some other content, including 30,000 TV series and 1000 movies, to third parties. However, this streaming strategy didn't win recognition from its investors reflected in the slump of the stock price at $16 \%$ after the launch of this strategy. Media analysts from LightShed Partners also suggested that ViacomCBS's streaming strategy is less clear compared to its competitors such as Disney+.

\subsection{Opportunities}

\subsubsection{Globalization}

With the growing importance of globalization, which has been fueled by internet technologies, ViacomCBS can cut costs by using online marketing strategies that appeal to a global audience.

More detailed information can be communicated via online advertisements; customers can take their time browsing information about products which may not be possible with above-the-line promotional techniques. ViacomCBS can also use embedded video clips, audio, and photos to promote its goods or services.

Considering the economic factor, the unemployment rate decreases in recent years, leading to higher income of customers, which generates more sales. On the other hand, recruiting employees in developing countries could be a beneficial plan for ViacomCBS. Since the unemployment rate is high in many developing countries, workers are cheaper in the labor market, which will lower the costs of recruitment. 


\subsubsection{COVID-19}

The pandemic of COVID-19 ceased the development of offline service, which provides an opportunity for ViacomCBS to establish online services and promote them above the line.

By using ATL promotion, ViacomCBS reaches a larger number of customers through televisions or the internet. For television, ViacomCBS owns a division called MTV, an American cable channel. Through various television channels on MTV, its customers could have access to music radios, documentaries of bands, and the latest music news, which makes MTV popular with young viewers and a leader in promoting a new type of rock and roll and rockers. MTV promotes popular cultures through its channels, helping it to attract more audiences. Additionally, Pluto TV, one of ViacomCBS's featured divisions, is a U.S. internet television service owned and operated by ViacomCBS Streaming.

Pluto TV is an HD and free video player, having content libraries from its content partners. On May 15, 2016, Pluto TV signed an agreement with Sony to make the Pluto TV app available on the PlayStation Store for download by users, which helps promote the contents of Pluto TV by reaching and attracting Sony's existing customers. In this way, Pluto TV enhances the brand image of its app and website and more customers are convinced to purchase, subscribe and download its products.

More detailed information can be communicated via online advertisements; customers can take their time browsing information.

\subsection{Threats}

\subsubsection{Strong Competitors}

ViacomCBS operates in the media industry which is fiercely competitive due to a large number of strong competitors such as Discovery Inc, Fox Corp, Netflix Inc, Walt Disney Co, and Warner Bros. Entertainment. These competitors all have strong competitiveness because they have a larger market share, better brand cognition and they exist in the market for a longer period comparing to ViacomCBS, which means ViacomCBS's competitors have existed customer base, relationships with distributors, and have more sources of finance. In addition, ViacomCBS may face the potential of being acquired by one of its competitors, like Walt Disney or Netflix. Apart from the threats of being acquired, ViacomCBS should be aware of the new entrants in this industry. When new media and entertainment company enters the market, they will gain market share from existing companies' market share.
This is a threat to Viacom as it can lose its market share and customers to these new entrants.

\subsubsection{Cybersecurity}

"Hackers have now gained access to the same resources that companies have," Brian, Senior Vice President Cloud Security and co-founder of DivvyCloud, said. "They can now ramp up their attack efforts to match our ability to defend ourselves." There's a shortage of cybersecurity professionals in the market, and the demand for those staff is huge, which indicates ViacomCBS should invest sufficient money in recruiting or training workers working for cybersecurity to beat the hackers.

\section{CONCLUSION}

ViacomCBS, based on the research of strategic management and the study of the company's background and developments and the prospects of the media industry, has great advantages in the development of the media industry. Although ViacomCBS has insufficient financing capabilities and room for improvement, the company's large customer base and resources pool, strong distribution network and liquidity situation, and potentials of integrated business model, make it possess great potential in the future development.

In summary, on the one hand, the conclusion of this article provides a new research background for the theory of strategic management, namely the study of Enterprise Strategy during the COVID-19 crisis, which broadens the theoretical application of enterprise strategy in the media industry; On the other hand, this article provides the theoretical basis for strategy transition and strategy formulation, which provides practical support for individual investors as well.

\section{REFERENCES}

[1] Song Dandan. (2016). Research on the diversified transformation and development of China's highspeed rail based on the theory of corporate strategic management. (Doctoral dissertation, China Academy of Railway Sciences).

[2] Mintzberg's 5Ps of Strategy - Explained. (2021). The Business Professor, LLC. https://thebusinessprofessor.com/mintzbergs-5psof-strategy

[3] Liu Jinhua. (2007). Research on the Development of Enterprise Strategic Management Theory. Shanxi Coking Coal Science and Technology (05), 36-39.

[4] Xu Jingming, \& Lin Xu. (2001). The evolution and development of enterprise strategic management 
theory. East China Economic Management (S1), 811.

[5] Chen Huailiang. Research on the Strategic Choice of Technological Innovation of Western Enterprises in my country. (Doctoral dissertation, Jiangxi University of Finance and Economics).

[6] Wang Xiuqiong. "New Progress in the Research of Enterprise Strategic Management_B Based on the Perspective of Institutional Economics and Organizational Sociology Institutional Theory." Journal of Hebei University of Economics and Trade v.32; No.167.04(2011): 16-21.

[7] Zha Jianqiu, Zhang Qiusheng, \& Zhuang Jian. (2009). An Empirical Study on the Relationship between Corporate Internal Control and Corporate Value under Strategic Management. Audit Research, 000(001), 76-80.

[8] Wang Qing. Research on the application of financial strategy management of $\mathrm{H}$ Bank from the perspective of internal control. (Doctoral dissertation, Hebei Normal University).

[9] Viacom and CBS will recombine as ViacomCBS after 13 years of operating as separate media companies. (2019, December 6). Business Insider. https://www.businessinsider.com/viacomcbsstreaming-video-supplier-strategy-is-its-biggestadvantage-201912 ?international $=$ true $\& \mathrm{r}=\mathrm{US} \& \mathrm{IR}=\mathrm{T}$

[10] About. (2020, November 26). ViacomCBS. https://www.viacomcbsnordics.com/en/viacomcbsnetworks-international/

[11] How SWOT (Strength, Weakness, Opportunity, and Threat) Analysis Works. (2021). Investopedia. https://www.investopedia.com/terms/s/swot.asp

[12] Tufts Libraries EZproxy Login. (2021, April 1). The Tufts Libraries. https://login.ezproxy.library.tufts.edu/login?url=htt ps://www-proquestcom.ezproxy.library.tufts.edu/reports/viacomcbsinc-viac-financial-strategicswot/docview/2475768768/se2 ? accountid $=14434+($ accessed + February $+8,+2021)$

[13] CBS Corporation Common Stock (VIAC: NASDAQ) Stock Price \& News. (2021, July 29). Google Finance. https://www.google.com/finance/quote/VIAC:NAS DAQ? window $=6 \mathrm{M}$ 